\title{
Tailoring the Protonic Conductivity of Porous Yttria-Stabilized Zirconia Thin Films by Surface Modification
}

1Received 00th January 20xx, Accepted 00th January 20xx

DOI: $10.1039 / x 0 x \times 00000 x$

\author{
Erdogan Celik*a, Rajendra S. Negi ${ }^{a}$, Michele Bastianello ${ }^{a}$, Dominic Boll ${ }^{\mathrm{b}}$, Andrey Mazilkin ${ }^{\mathrm{b}}$, Torsten \\ Brezesinskib ${ }^{b}$ Matthias T. Elm*a,c,d
}

\begin{abstract}
Porous yttria-stabilized zirconia (YSZ) thin films were prepared by pulsed laser deposition to investigate the influence of specific surface area on the electrical and protonic transport properties. Electrochemical impedance spectroscopy was carried out as a function of temperature, oxygen activity and humidity of the surrounding atmosphere. At high humidity, protons on the surface of the porous YSZ thin films lead to increased conductivity, even for temperatures up to $700{ }^{\circ} \mathrm{C}$. With increasing relative humidity, the activation energy of proton transport decreases because of changes in the transport mechanism from Grotthuss-type to vehicle-type transport. By coating the porous YSZ films with an amorphous titania ( $\left.\mathrm{TiO}_{2}\right)$ layer of only few nanometer thickness using atomic layer deposition, the protonic contribution to conductivity is significantly reduced. Depositing an $18 \mathrm{~nm}$-thick anatase $\mathrm{TiO}_{2}$ surface layer, the protonic conductivity contribution increases again, which can be attributed to enhanced capillary condensation because of the lower pore size. Interestingly, the filling of pores is accompanied by a decrease in proton mobility. Theses results demonstrate the significant effect that the porosity and the surface properties have on the protonic transport and further provide new design principles for developing nanostructured proton-conducting oxides.
\end{abstract}

\section{Introduction}

Besides tailoring the composition, the properties of oxide ceramics can also be altered by nanostructuring, ${ }^{1-4}$ i.e., by increasing the density of interfaces, such as grain boundaries or free surface. The reason is that, because of the formation of a space charge region, the defect chemistry at interfaces differs significantly from that of the bulk, ${ }^{5-10}$ resulting in changes in electronic and oxygen ion conductivity of the nanostructured material (especially when the interfaces dominate the overall behavior). Additionally, nanostructured oxides attracted much interest in recent years, since a significant increase in protonic conductivity at low temperatures has been reported for several materials, such as $\mathrm{Y}_{2} \mathrm{O}_{3}$-stabilized $\mathrm{ZrO}_{2}$ (YSZ), ${ }^{11-13} \mathrm{CeO}_{2}{ }^{14-17}$ and $\mathrm{TiO}_{2} \cdot{ }^{18-21}$ Because of their protonic conductivity at ambient conditions, these materials are interesting for applications as sensors, ${ }^{22-24}$ in energy storage and conversion ${ }^{12,25}$ or heterogeneous catalysis. ${ }^{26}$

Although there are many literature reports on proton conductivity in oxide materials, the transport mechanisms in fluorite-type oxides are still under debate. The measurements

\footnotetext{
a. Center for Materials Research, Justus-Liebig-University Giessen, Heinrich-Buff Ring 16, 35392 Giessen, Germany.E-mail:, matthias.elm@phys.chemie.unigiessen.de

b. Institute of Nanotechnology, Karlsruhe Institute of Technology (KIT), Hermannvon-Helmholtz Platz 1, 76344 Eggenstein-Leopoldshafen, Germany.

. Institute of Physical Chemistry, Justus-Liebig-University Giessen, Heinrich-Buff Ring 17, 35392 Giessen, Germany.

d. Institute of Experimental Physics I, Justus-Liebig-University Giessen, Heinrich-Buff Ring 16, 35392 Giessen, Germany.
}

conducted on dense hydrated ceria and zirconia showed no evidence of proton conductivity, ${ }^{14}$ indicating that proton transport in the bulk is negligible and the protonic conductivity in nanomaterials can be directly related to the nanostructure. In principle, it is not obvious whether a large specific surface area or a high grain boundary density is decisive for this effect. Studies by Avila-Paredes et al. and Chiodelli et al. suggested that the grain size has a significant effect on the protonic conductivity ${ }^{15,27-29}$ and protonic transport occurs along the grain boundaries. On the other hand, a blocking behavior of the grain boundary for protons was reported, caused by the positively charged space charge region hindering proton transport. ${ }^{30,31}$ However, most studies attribute the enhanced protonic conductivity at low and intermediate temperatures to the presence of transport paths along the pores and/or the inner sample surface. ${ }^{12-14,32,33}$ Water molecules adsorbed at the surface can then contribute by two different transport mechanisms depending on the relative humidity in the surrounding atmosphere and the temperature. While for low water content and high temperatures a Grotthuss mechanism is responsible for protonic transport, at higher water partial pressure the proton conductivity arises from vehicle transport of $\mathrm{H}_{3} \mathrm{O}^{+}$molecules. ${ }^{11,13,33}$ Although a high surface area seems to be beneficial for protonic transport up to $500{ }^{\circ} \mathrm{C}, 11,12,34$ the results on mesoporous YSZ thin films with a large specific surface area revealed no indication of proton conductivity, but instead a decrease in total conductivity under humidified atmosphere. ${ }^{35}$ These results indicate that not only the surface area, but also the pore size and surface chemistry affect the protonic (surface) conductivity in nanostructured oxides. 
Here, we report on the influence of surface modification on the protonic conductivity in porous YSZ thin films prepared by pulsed laser deposition (PLD). Because of their high surface-tovolume ratio, porous materials present an ideal model system to study the effect of surface on the transport properties. Furthermore, the surface properties can be tailored, which is useful to gain a basic understanding of the influence of surface on the electrochemical properties. The electrochemical impedance measurements as a function of temperature and for different water contents in the atmosphere reveal that the porous YSZ thin films exhibit protonic conductivity contribution even at high temperatures of $700{ }^{\circ} \mathrm{C}$. By surface coating with an amorphous titania $\left(\mathrm{aTiO}_{2}\right)$ film of about $6 \mathrm{~nm}$ thickness using atomic layer deposition (ALD), the protonic contribution is suppressed at temperatures above $120{ }^{\circ} \mathrm{C}$. Increasing the thickness of the $\mathrm{TiO}_{2}$ layer results in a crystalline $\mathrm{TiO}_{2}\left(\mathrm{cTiO}_{2}\right)$ coating and reduced pore size, which not only increases the surface protonic conductivity contribution again, but interestingly also results in a change in activation energy at high water content, thus indicating an altered proton transport mechanism. Overall, the results emphasize the significant effect that surface modification has on the protonic conductivity in porous oxide materials.

\section{Experimental Section}

Porous thin films of 9.5 mol\% YSZ were deposited on (0001)oriented single-crystalline sapphire substrates using PLD at 10 $\mathrm{Pa}$ oxygen background pressure and $300{ }^{\circ} \mathrm{C}$ substrate temperature. The deposition was performed with a KrF-excimer laser, a repetition rate of $10 \mathrm{~Hz}$, and with a distance of $6 \mathrm{~cm}$ between the substrate and the target. The laser fluence was set to about $2.3 \mathrm{~J} / \mathrm{cm}^{2}$. After deposition, the films were annealed for 3 days at $800{ }^{\circ} \mathrm{C}$, resulting in a porous structure. After annealing, the films exhibit a thickness of approximately $70 \mathrm{~nm}$. Interdigitated platinum microelectrodes ${ }^{36}$ were prepared on the top surface of the porous thin films using photolithography. For this, a positive photoresist (ma-P 1215, micro resist technology $\mathrm{GmbH}$ ) was used. The platinum electrodes with a thickness of $200 \mathrm{~nm}$ were deposited by electron-beam evaporation. The interdigitated electrodes used consist of 21 fingers of $3 \mathrm{~mm}$ length and $47 \mu \mathrm{m}$ width, with the distance between the fingers being $33 \mu \mathrm{m}$.

For structural investigations, the scanning electron microscopy (SEM) images were taken with a MERLIN from Carl Zeiss at $5 \mathrm{kV}$. The grazing incidence $X$-ray diffraction (GIXRD) measurements were performed at an angle of incidence of $1^{\circ}$ on an $X^{\prime}$ Pert PRO MRD from PANalytical instruments $(\lambda=0.15406 \mathrm{~nm}$ ). The Raman measurements were carried out on an inVia Raman microscope from Renishaw in backscattering geometry $(\lambda=633$ $\mathrm{nm}$ ). Electrochemical impedance spectroscopy (EIS) was performed in the frequency range from $10 \mathrm{MHz}$ to $10 \mathrm{mHz}$ at an AC amplitude of $100 \mathrm{mV}$ using a Novocontrol Alpha-A impedance analyzer. The oxygen partial pressure in the gas atmosphere was controlled by gas mixtures of $\mathrm{O}_{2}$ and Ar. The impedance spectra were evaluated using the software RelaxIS $3 .{ }^{37}$
$\mathrm{TiO}_{2}$ was deposited by ALD on two YSZ thin films using an ALD R200 Standard system from Picosun. Tetrachloride $\left(\mathrm{TiCl}_{4}\right)$ and water were used as precursors at a substrate temperature of $150{ }^{\circ} \mathrm{C}$. Under these conditions, the growth rate of $\mathrm{TiO}_{2}$ was determined to be $0.06 \mathrm{~nm}$ per cycle. The $\mathrm{TiO}_{2}$ coatings had thicknesses of 6 and $18 \mathrm{~nm}$. Transmission electron microscopy (TEM) was performed on an FEl Titan 80-300 aberrationcorrected (image) microscope operated at $300 \mathrm{kV}$. The samples for TEM investigations were prepared using the FEI STRATA 400 $S$ dual-beam system, with the Ga-ion beam operating at $30 \mathrm{kV}$, followed by final polishing at $2 \mathrm{kV}$ for the surface quality improvement. Energy-filtered (EF) TEM was carried out with an image filter (Gatan Tridium 863) using the $\mu$-probe EFTEM setup. The $\mathrm{Zr} \mathrm{M}_{45}, \mathrm{O} \mathrm{K}$ and Ti $\mathrm{L}_{32}$ edges were used to determine the spatial distribution of the corresponding elements.

\section{Structural Characterization}

The representative top view SEM images of the porous YSZ thin film before and after annealing at $800^{\circ} \mathrm{C}$ are shown in Figs. 1 (a) and 1 (b), respectively. While the as-deposited YSZ thin film shows a relatively smooth surface, the material exhibits grains in the size range of 15 to $20 \mathrm{~nm}$ and increased porosity after the annealing step. Image processing using Otsu's method ${ }^{38}$ revealed a porosity of $47 \%$ and an average pore size of ( $43 \pm$ 2) $\mathrm{nm}$.


Figure 1. SEM images of (a) as-deposited, (b) porous (annealed), (c) 6 $\mathrm{nm}$ and (d) $18 \mathrm{~nm} \mathrm{TiO}{ }_{2}$ ALD-coated YSZ thin films.

To modify the surface properties and to vary the pore size, the porous YSZ thin films were coated with a $\mathrm{TiO}_{2}$ layer of thicknesses 6 and $18 \mathrm{~nm}$ using ALD. SEM images of the resulting thin films are shown in Figs. 1 (c) and (d). It can clearly be seen that the pore size decreases compared to that of uncoated YSZ thin film shown in Fig. 1 (b). The porosity estimated from the SEM images was $43 \%$ and $38 \%$, respectively. Because of the $\mathrm{TiO}_{2}$ coating, the average pore size was also significantly reduced to $(29 \pm 2) \mathrm{nm}$ and $(18 \pm 2) \mathrm{nm}$, respectively. 
Apart from SEM, the structural properties of the thin films were characterized by GIXRD. This method provides a way to avoid the strong reflections from the substrate and thus only the crystal structure of the material of interest is probed. The GIXRD pattern of an annealed YSZ thin film is shown in Fig. 2 (a). Investigation of the coated YSZ films showed no differences because of the low thickness of the $\mathrm{TiO}_{2}$ layer. The thin films exhibit the expected reflections of cubic YSZ according to the reference data. ${ }^{39}$ The absence of additional reflections confirms the deposition of a single-phase material. Using the Scherrer equation, ${ }^{40}$ the crystallite size was calculated to be about 17 $\mathrm{nm}$, in good agreement with the values estimated from SEM imaging.


Figure 2. (a) GIXRD pattern of porous (annealed) YSZ. For comparison, the reference pattern of cubic YSZ is also shown. (b) Raman spectra of porous (annealed) $\mathrm{YSZ}, \mathrm{YSZ}_{\mathrm{aTiO}}(6 \mathrm{~nm})$ and $\mathrm{YSZ} / \mathrm{cTiO}_{2}(18 \mathrm{~nm})$.

However, because of the small scattering factor of oxygen and the broad reflections caused by the small crystallites, it is difficult to distinguish between the cubic and the tetragonal phases of YSZ by XRD. ${ }^{41,42}$ For reliable assessment of the crystal structure, the thin films were also probed using Raman spectroscopy. The Raman spectra of the uncoated and coated YSZ thin films are shown in Fig. 2 (b). For the uncoated YSZ thin film and that with $6 \mathrm{~nm} \mathrm{TiO}$, only two modes are observed. The mode at $420 \mathrm{~cm}^{-1}$ arises from the sapphire substrate ${ }^{43,44}$, while the second mode $\left(F_{2 g}\right)$ at about $640 \mathrm{~cm}^{-1}$ is characteristic of the cubic fluorite-type phase of YSZ. ${ }^{35,45}$ No indication of the $\mathrm{TiO}_{2}$ coating is observed, thus suggesting deposition of an amorphous $\left(\mathrm{aTiO}_{2}\right)$ layer. The YSZ thin film coated with $18 \mathrm{~nm}$ $\mathrm{TiO}_{2}$ exhibits four additional modes at $143\left[E_{\mathrm{g}}(1)\right], 196\left[\mathrm{E}_{\mathrm{g}}(2)\right]$,
$379\left[\mathrm{~B}_{1 \mathrm{~g}}\right]$ and $516 \mathrm{~cm}^{-1}\left[\mathrm{~A}_{1 \mathrm{~g}}\right]$, confirming the successful deposition of anatase $\mathrm{TiO}_{2}\left(\mathrm{cTiO}_{2}\right)$ with tetragonal symmetry. ${ }^{46-}$ ${ }^{48}$ From the literature, it is known that, below a critical thickness of approximately $6 \mathrm{~nm}$, ALD-derived titania layers are amorphous in nature ${ }^{49}$ in agreement with the Raman results.

To confirm the successful coating of the surface, HRTEM measurements were performed. In Fig. 3 (a), the HRTEM image is shown for the $\mathrm{YSZ}$ sample with a $6 \mathrm{~nm}$-thick $\mathrm{TiO}_{2}$ coating. The absence of any crystalline phase in the $\mathrm{TiO}_{2}$ layer corroborates the amorphous structure. Furthermore, the EFTEM image shown in Fig. 3 (b) indicates conformal and homogenous surface coating of the pores in the YSZ thin film.
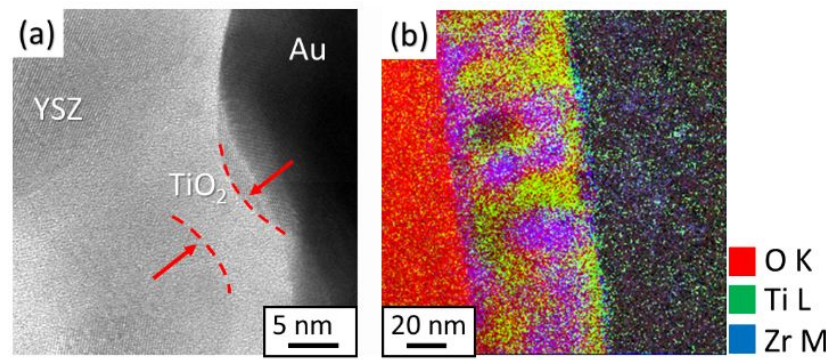

Figure 3. (a) HRTEM image of $\mathrm{YSZ}_{\mathrm{aTiO}}(6 \mathrm{~nm})$ and (b) EFTEM image demonstrating the uniformity of the amorphous titania coating.

\section{Electrochemical Characterization}

\section{Dry atmosphere}

The electrical conductivity of the porous YSZ thin film was investigated by impedance spectroscopy in the temperature range between 200 and $700{ }^{\circ} \mathrm{C}$ and for varying oxygen partial pressure and humidity. The representative impedance spectra (Nyquist representation) recorded at ambient oxygen partial pressure, i.e., $\lg \left(p\left(\mathrm{O}_{2}\right)\right)=-0.67$, at $965 \mathrm{~K}$ under dry and ambient atmospheres are shown in Fig. 4. Under dry conditions and at low temperatures, a nearly ideal semicircle is observed at high frequencies. With increasing temperature, the Nyquist plot shows the onset of a second semicircle at low frequencies (not shown) and, finally, at high temperatures [Fig. 4 (a)], a third semicircle is observed. Under ambient conditions, i.e., $20.2 \%$ relative humidity [Fig. 4 (b)], the resistance of the highfrequency semicircle is significantly reduced, indicating that the humidity has a significant effect on the transport properties, even at high temperatures. 
a)



b)

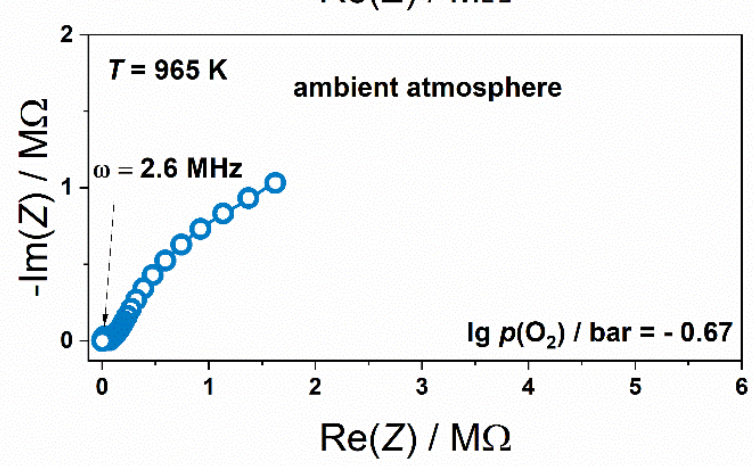

Figure 4. Impedance spectra of porous (annealed) YSZ at high temperature and under dry (black) and ambient atmosphere conditions (blue).

To determine the total resistance of the thin films, the impedance spectra were fitted using an equivalent circuit consisting of three $R Q$ elements in series (solid lines in Fig. 4). For the high frequency semicircle, a capacitance of about $5 \cdot 10^{-12} \mathrm{~F}$ was determined, while for the second semicircle a capacitance of about $9 \cdot 10^{-11} \mathrm{~F}$ is found. The first semicircle can be attributed to the response of the bulk material, which typically shows capacitances between $10^{-12}$ and $10^{-10} \mathrm{~F}$. The second semicircle corresponds to the response of the grain boundaries, exhibiting capacitances in the range between $10^{-10}$ and $10^{-8} \mathrm{~F}$ depending on the grain size. ${ }^{50-53}$ For nanostructured materials, the capacity typically shifts to lower values, often resulting in an overlap of the bulk and the grain boundary semicircles. ${ }^{1,35}$ The semicircle at low frequency with a capacitance of about $1 \cdot 10^{-7} \mathrm{~F}$ corresponds to the electrochemical response of the electrode-electrolyte interface. ${ }^{37,50}$ As the scope of this study is to take a closer look on the transport processes of the electrolyte, we did not investigate the electrode processes in detail. The total conductivity was calculated from the total resistance $R$, i.e., the bulk and the grain boundary resistance, according to:

$$
\sigma=\frac{1 l}{R b d}
$$

where $l$ denotes the electrode distance, $b$ is the electrode length and $d$ is the thickness of the porous thin film. Note that, by using equation (1), the porosity is neglected, i.e., a dense thin film is assumed. Thus, the obtained values underestimate the total conductivity and should be rather seen as a kind of lower limit.
The temperature dependence of the total conductivity of the porous YSZ thin film under the dry atmosphere and for varying humidity is presented in Fig. 5 (a). At dry conditions, the conductivity shows a linear Arrhenius-type behavior over the whole temperature range, caused by a dominant oxygen ion conductivity. The high oxygen ion conductivity in YSZ arises from the isoelectric doping of zirconia with yttria, generating oxygen vacancies $\left(\mathrm{V}_{\mathrm{O}}^{\bullet}\right)$ to maintain charge neutrality. Using Kroeger-Vink notation, the doping is described by: ${ }^{54,55}$

$$
\mathrm{Y}_{2} \mathrm{O}_{3} \stackrel{\mathrm{ZrO}_{2}}{\longrightarrow} 2 \mathrm{Y}_{\mathrm{Zr}}^{\prime}+\mathrm{V}_{\mathrm{O}}^{\bullet \bullet}+3 \mathrm{O}_{\mathrm{O}}^{\mathrm{x}}
$$

where $\mathrm{Y}_{\mathrm{Zr}}^{\prime}$ denotes an $\mathrm{Y}^{3+}$ in the $\mathrm{Zr}^{4+}$ lattice site with a relative charge of -1 and $\mathrm{V}_{\mathrm{O}}^{\bullet \cdot}$ is the vacancy in the oxygen lattice site with a relative charge of $+2 . \mathrm{O}_{\mathrm{O}}^{\mathrm{X}}$ denotes the lattice oxygen with a charge of zero. By changing the oxygen partial pressure, the conductivity remains constant as shown in Fig. 5 (d), also confirming that the oxygen ions are the dominant charge carriers. ${ }^{35,54}$

The total conductivity $\sigma(T)$ of the YSZ thin film is given by:

$$
\sigma(T)=\frac{\sigma_{0, \text { ion }}}{T} \exp \left(-\frac{E_{\mathrm{A}, \text { ion }}}{k_{\mathrm{B}} T}\right)
$$

where $k_{\mathrm{B}}$ is the Boltzmann constant, $E_{\mathrm{A} \text {,ion }}$ is the activation energy representing the migration enthalpy of the oxygen ions $\Delta H_{\mathrm{mig}}$, and $\sigma_{0, \text { ion }}$ is the conductivity pre-factor of the oxygen ions. By fitting the linear behavior in the Arrhenius representation using the expression:

$$
\ln (\sigma T)=\ln \sigma_{0, \text { ion }}-\frac{E_{A}}{k_{\mathrm{B}} T}
$$

an activation energy $E_{\mathrm{A}, \mathrm{ion}}=(1.09 \pm 0.03) \mathrm{eV}$ was determined, which is in good agreement with values in the range of 0.8-1.2 eV typically reported for oxygen ion conductivity in YSZ. ${ }^{54,56-58}$ For the conductivity pre-factor, a value of $\sigma_{0, \text { ion }}=5.7 \cdot 10^{8} \mathrm{~s}$. $\mathrm{K} / \mathrm{m}$ was obtained. The fits according to equation (3) are shown in Fig. 5 (d) as dashed lines.

After ALD coating with $6 \mathrm{~nm}$ amorphous $\mathrm{TiO}_{2}\left(\mathrm{aTiO}_{2}\right)$, the porous thin film reveals a distinct change in the temperature dependence of conductivity. Two transport regimes with different activation energies are observed in the Arrhenius representation, as shown in Fig. 5 (b). 


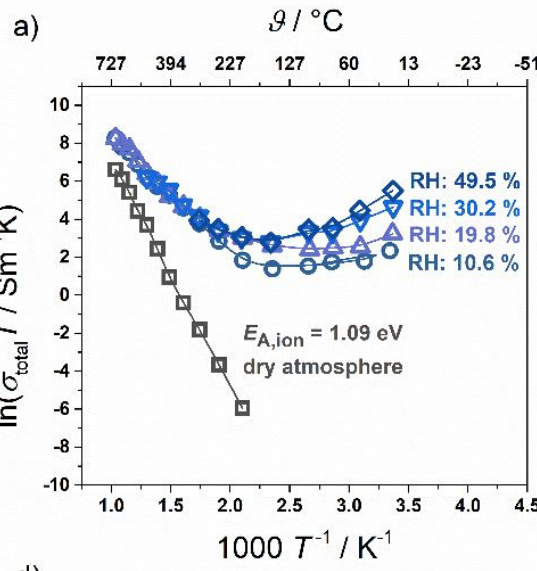

d)

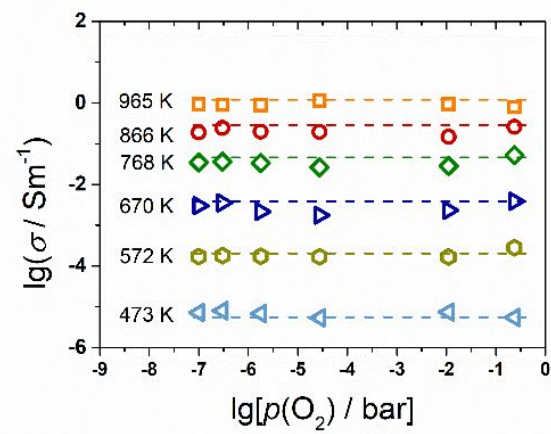

b) $\quad 9 /{ }^{\circ} \mathrm{C}$

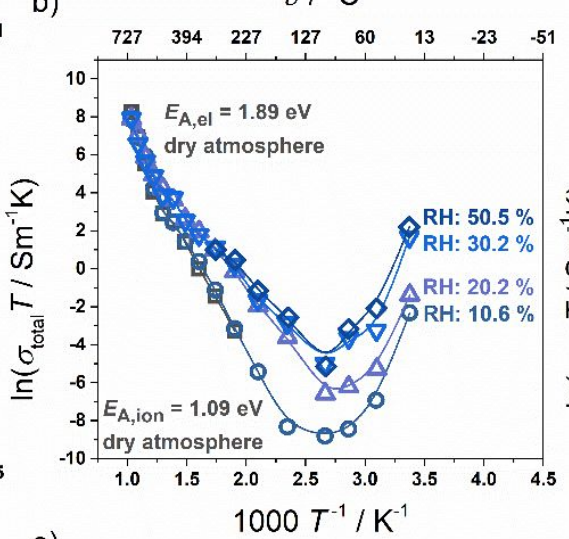

e)

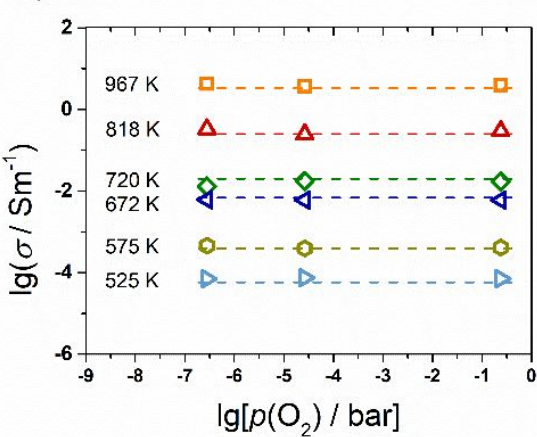

c)

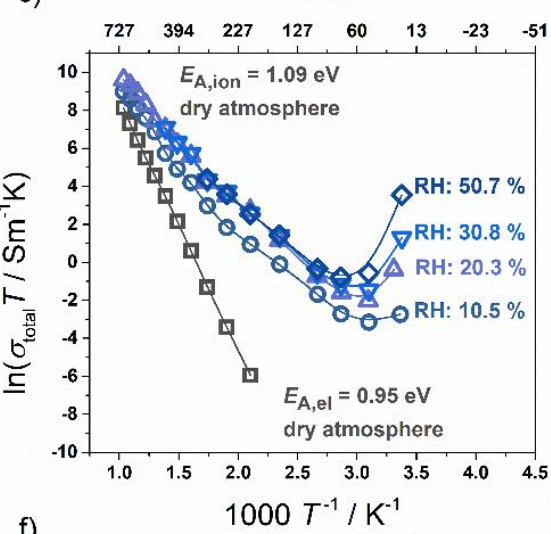

f)



Figure 5. Arrhenius plots of the total conductivity for (a) porous (annealed) YSZ, (b) $\mathrm{YSZ}_{\mathrm{aTiO}}$ (6 nm) and (c) YSZ/cTiO 2 (18 nm). Oxygen partial pressure dependence of the total conductivity for (d) porous (annealed) YSZ, (e) $\mathrm{YSZ} / \mathrm{aTiO}_{2}(6 \mathrm{~nm})$ and (f) YSZ/cTiO 2 (18 nm).

At low temperatures, the transport is again dominated by oxygen vacancies, as confirmed by a constant conductivity with varying oxygen partial pressure. Above $500{ }^{\circ} \mathrm{C}$, the activation energy significantly increases, which is attributed to an additional conductivity contribution arising from electrical transport in the $\mathrm{aTiO}_{2}$ layer. The total conductivity is then given by:

$$
\sigma_{\text {tot }}(T)=\frac{\sigma_{0, \text { ion }}}{T} \exp \left(-\frac{E_{\mathrm{A}, \mathrm{ion}}}{k_{\mathrm{B}} T}\right)+\sigma_{0, \mathrm{el}} \exp \left(-\frac{E_{\mathrm{A}, \mathrm{el}}}{k_{\mathrm{B}} T}\right)
$$

where $E_{\mathrm{A}, \mathrm{el}}$ and $\sigma_{0, \mathrm{el}}$ are the activation energy and the conductivity pre-factor of the electronic charge carriers, respectively. In amorphous semiconductors, electrical transport at high temperatures arises from thermal activation of electrons from the valence band mobility edge to the conduction band mobility edge, i.e., the formation of an electron-hole pair. The activation energy is then given by: ${ }^{59}$

$$
E_{\mathrm{A}, \mathrm{el}} \approx \frac{E_{\mathrm{g}}}{2}
$$

with $E_{\mathrm{g}}$ being the band gap of the material. Using equation (5), the fit to the experimental data shown as dashed lines in Fig. 5 (e) revealed an activation energy $E_{\mathrm{A}, \mathrm{ion}}=(1.09 \pm 0.05) \mathrm{eV}$ for the ionic conductivity contribution, in agreement with the uncoated YSZ thin film, and a slightly higher pre-factor $\sigma_{0, \text { ion }}$
$=(8 \pm 0.2) \cdot 10^{8} \mathrm{~S} \cdot \mathrm{K} / \mathrm{m}$. For the electronic contribution, an activation energy $E_{\mathrm{A}, \mathrm{el}}=(1.89 \pm 0.02) \mathrm{eV}$ and a pre-factor $\sigma_{0, \mathrm{el}}$ $=7.5 \cdot 10^{9} \mathrm{~S} \cdot \mathrm{K} / \mathrm{m}$ were determined. Amorphous $\mathrm{TiO}_{2}$ exhibits an energetic band energy of approximately 3.3-3.5 eV60,61 and, thus, an activation energy of 1.7-1.8 eV is expected, which is in good agreement with the observed value of $1.89 \mathrm{eV}$.

Finally, Fig. 5 (c) shows the temperature dependence of conductivity for the porous YSZ thin film coated with $18 \mathrm{~nm}$ $\mathrm{TiO}_{2}$. Again, two transport regimes of different activation energy are observed under dry conditions, although their difference is not as pronounced as for the sample with the $6 \mathrm{~nm}$ $\mathrm{TiO}_{2}$ coating. In Fig. 5 (f), the $p\left(\mathrm{O}_{2}\right)$-dependence is shown for the conductivity in the investigated temperature range. At low temperatures, the conductivity decreases, with the characteristic $-1 / 6$ Brouwer slope for increasing $p\left(\mathrm{O}_{2}\right)$. At high temperatures, a decrease in conductivity is only observed for low oxygen partial pressures, while at high $p\left(\mathrm{O}_{2}\right)$, the conductivity remains constant. The observed behavior is again attributed to an additional electronic contribution of the $\mathrm{cTiO}_{2}$ coating to the total conductivity of the porous YSZ thin film, as the observed slope of $-1 / 6$ is typical of anatase under reducing conditions. ${ }^{62-64}$ In this regime, oxygen vacancies are formed in $\mathrm{TiO}_{2}$ which is accompanied by an increase in electron concentration. In Kroeger-Vink notation, the reduction reaction can be written as: 


$$
\mathrm{O}_{\mathrm{O}}^{\mathrm{x}} \rightleftharpoons \mathrm{V}_{\mathrm{O}} \ddot{0}+2 \mathrm{e}^{\prime}+1 / 2 \mathrm{O}_{2}
$$

with the equilibrium constant

$$
K_{\text {Red }}=K_{0} \exp \left(-\frac{\Delta G_{\mathrm{f}}}{k_{\mathrm{B}} T}\right)=\left[\mathrm{V}_{\mathrm{O}} \cdot\right]\left[\mathrm{e}^{\prime}\right]^{2} p\left(\mathrm{O}_{2}\right)^{\frac{1}{2}}
$$

where $\Delta G_{\mathrm{f}}$ denotes the Gibbs free enthalpy for the formation of oxygen vacancies. Using the Brouwer approximation for this regime, $\left[\mathrm{e}^{\prime}\right]=2\left[\mathrm{~V}_{\mathrm{O}}^{\bullet \bullet}\right]$, the increase in electron concentration as a function of oxygen partial pressure is given by: 62

$$
\left[\mathrm{e}^{\prime}\right] \propto p\left(\mathrm{O}_{2}\right)^{\frac{1}{6}}
$$

While at low oxygen partial pressure the electrons dominate the overall conductivity, as shown in Fig. 5 (f), at high temperatures and oxygen partial pressure, the constant conductivity arises from the ionic plateau of the porous YSZ. Thus, the total conductivity of the $18 \mathrm{~nm} \mathrm{TiO}{ }_{2}$-coated YSZ thin film is given by:

$$
\begin{gathered}
\sigma_{\text {tot }}(T)=\sigma_{\text {ion }}(T)+\sigma_{\text {elec }}(T) \\
\propto \frac{\sigma_{0, \text { ion }}}{T} \exp \left(-\frac{E_{\mathrm{A}, \text { ion }}}{k_{B} T}\right)+\frac{\sigma_{0, \text { el }}^{\prime}}{T} \exp \left(-\frac{E_{\mathrm{A}, \mathrm{el}}}{k_{B} T}\right) p\left(\mathrm{O}_{2}\right)^{-\frac{1}{6}}
\end{gathered}
$$

where $E_{\mathrm{A} \text {,ion }}$ is the migration enthalpy of the oxygen ions and $E_{\mathrm{A}, \mathrm{el}}=\Delta H_{\mathrm{f}} / 3$ is the activation energy related to the formation enthalpy $\Delta H_{\mathrm{f}}$ of the titania layer. The fit to the total conductivity using equation (10) is shown as solid lines in Fig. 5 (c). For the oxygen ions, an activation energy $E_{\mathrm{A} \text {,ion }}=(1.09 \pm 0.2) \mathrm{eV}$ is obtained, again in good agreement with the value determined for the uncoated sample. The electronic contribution shows an activation energy $E_{\mathrm{A}, \mathrm{el}}=(0.95 \pm 0.03) \mathrm{eV}$, which is in the range of $0.89-0.98 \mathrm{eV}$ reported for porous anatase, 65,66 thereby confirming the additional electronic contribution of the surface coating to the total conductivity of the coated YSZ thin film. The pre-factors are $\sigma_{0, \text { ion }}=1 \cdot 10^{9} \mathrm{~s} \cdot \mathrm{K} / \mathrm{m}$ and $\sigma_{0, \text { el }}=2.1 \cdot 10^{7} \mathrm{~s}$. $\mathrm{K} /(\mathrm{m} \cdot \mathrm{bar})$.

\section{Humid atmosphere}

To study the influence of porosity and surface coating on the protonic conductivity, the electrochemical impedance measurements were performed under varying relative humidity $(\mathrm{RH})$ in the same temperature range. As shown in Fig. 5 (a), the porous YSZ thin film exhibits a significant increase in conductivity even for a low $\mathrm{RH}$ of $10.6 \%$. The presence of humidity leads to the formation of a water film at the top surface and thus to protonic surface conductivity, which increases with increasing $\mathrm{RH}$ by several orders of magnitude, in agreement with reports available in literature. ${ }^{12-15,18,20}$ At temperatures above $150{ }^{\circ} \mathrm{C}$ and/or low humidity, only chemisorbed layers exist, consisting of hydroxyl groups bonded to the oxide and relatively strong hydrogen bonded water molecules. ${ }^{11,13,67}$ The chemisorbed species are reported to be stable up to $600{ }^{\circ} \mathrm{C}$ and $200{ }^{\circ} \mathrm{C}$, respectively. ${ }^{11,13,33,67}$ The mechanism for the adsorption of water on an ideal surface is given by: ${ }^{11}$

$\mathrm{Zr}-\mathrm{O}-\mathrm{Zr}+\mathrm{H}_{2} \mathrm{O} \leftrightarrow \mathrm{Zr}-\mathrm{O}+\mathrm{Zr}-\mathrm{OH}_{2} \leftrightarrow \mathrm{Zr}-\mathrm{OH}+\mathrm{Zr}-\mathrm{OH}$

However, also surface defects, such as oxygen vacancies, play a significant role in the formation of surface protons as water fills the oxygen vacancies and forms hydroxyl groups. ${ }^{68-70}$ In Kroeger-Vink notation, their formation is given by the reaction: ${ }^{15,35,71,72}$

$$
\mathrm{H}_{2} \mathrm{O}_{(\mathrm{g})}+\mathrm{V}_{\mathrm{O}}^{\bullet \bullet}+\mathrm{O}_{\mathrm{O}}^{\mathrm{x}} \leftrightarrow 2(\mathrm{OH})_{\mathrm{O}}^{\bullet}
$$

In the chemisorbed layer, the proton transport is expected to occur because of the formation of defects and proton hopping (Grotthuss-type mechanism): ${ }^{11}$

$$
2[\mathrm{Zr}-\mathrm{OH}] \leftrightarrow \mathrm{ZrOH}_{2}^{+}+\mathrm{ZrO}^{-}
$$

By combining equations (9) and (10), the water partial pressure dependence of the protonic defects is given by: ${ }^{17,34,72}$

$$
\left[\mathrm{ZrOH}_{2}^{+}\right] \propto[\mathrm{Zr}-\mathrm{OH}] \propto p_{\mathrm{H}_{2} \mathrm{O}}^{1 / 2}
$$

The conductivity as a function of water partial pressure is shown in Fig. 6. As the conductivity is proportional to the charge carrier defects, the observed slope of approximately $1 / 2$ confirms a dominant protonic conductivity under humidified conditions.

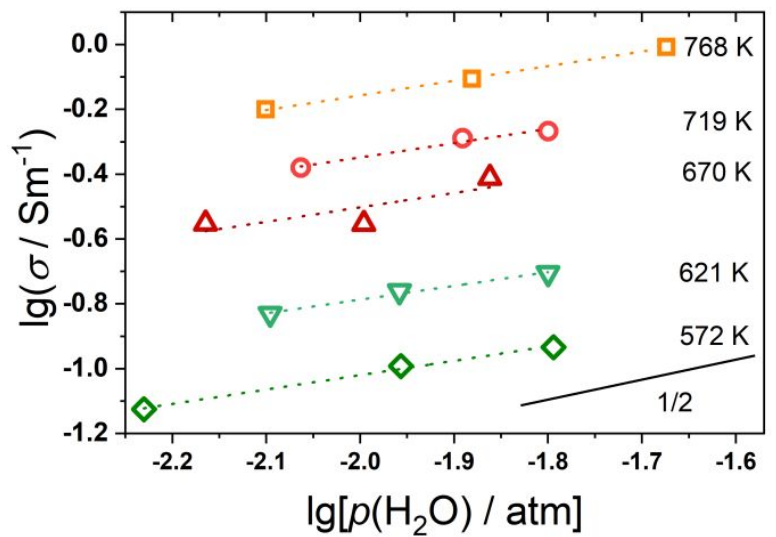

Figure 6. Protonic conductivity of porous (annealed) YSZ depending on the water vapor partial pressure.

At lower temperatures, the physisorption of water molecules takes place and, at a $\mathrm{RH} \approx 30 \%$, an "ice-like" layer with an additional physisorbed layer is formed. With increasing $\mathrm{RH}$, the number of physisorbed water layers further increases and, for $\mathrm{RH}>60 \%$, the transport is expected to take place by hydronium ions via vehicle mechanism. ${ }^{11,13,33}$

$$
\mathrm{Zr}-\mathrm{OH}_{2}+\mathrm{H}_{2} \mathrm{O} \leftrightarrow \mathrm{Zr}-\mathrm{OH}^{-}+\mathrm{H}_{3} \mathrm{O}^{+}
$$

Interestingly, for the porous thin films studied in this work, the protonic contribution is significantly higher compared to other literature reports. ${ }^{12,13,15}$ For example, even at $700{ }^{\circ} \mathrm{C}$, a protonic contribution is clearly observed, while typically an increase in conductivity under humidified conditions is only found for temperatures up to $400{ }^{\circ} \mathrm{C}$.

The large increase in protonic conductivity indicates that the nanostructure and the pore size is crucial for the incorporation of water and the transport of protons along inner surfaces of 

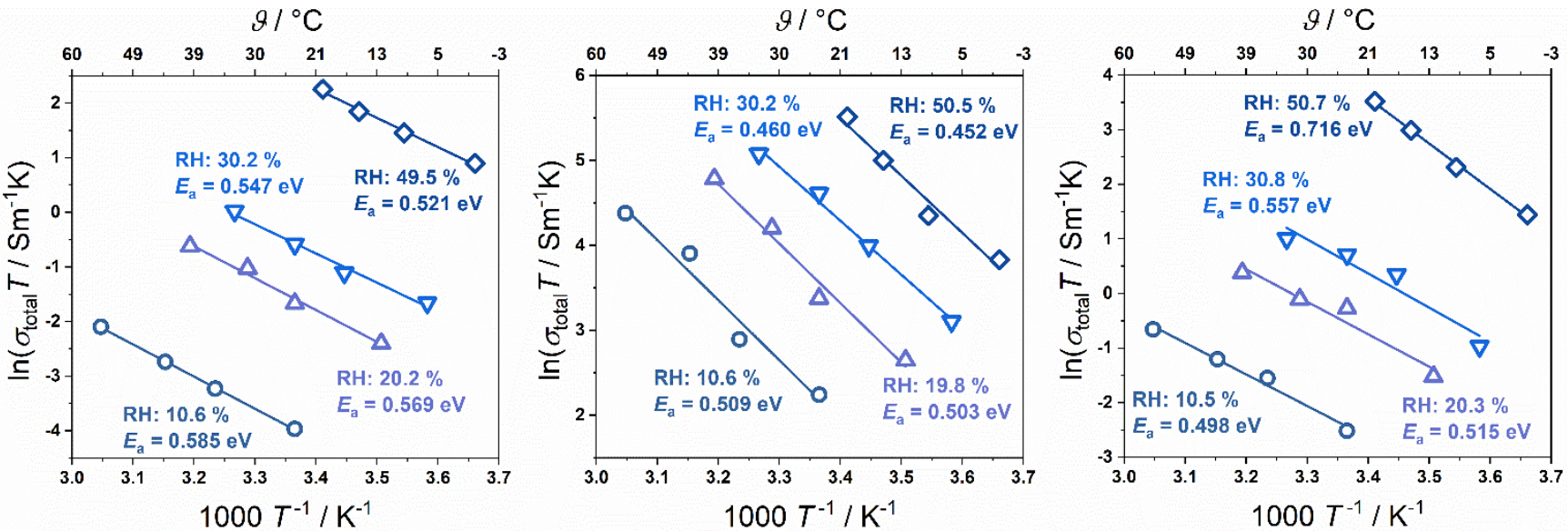

Figure 7. Determination of the activation energy of protonic conduction for temperatures below $100{ }^{\circ} \mathrm{C}$ : (a) porous (annealed) $\mathrm{YSZ}$, (b) $\mathrm{YSZ} / \mathrm{aTiO}$ $(6 \mathrm{~nm})$ and $(\mathrm{c}) \mathrm{YSZ}_{\mathrm{CTTO}}(18 \mathrm{~nm})$.

the oxide, in agreement with previous studies. Miyoshi et al. observed a comparable protonic contribution up to $650{ }^{\circ} \mathrm{C}$ for nano-grained YSZ. ${ }^{33,34}$ They attributed the high conductivity under "wet" conditions to hopping transport of protons in interfacial hydrated layers within the YSZ material. Likewise, Gregori et al. ascribed the protonic conductivity of nanocrystalline samples to the presence of a water layer formed in residual pore openings due to capillary condensation. ${ }^{14}$ However, sol-gel derived YSZ thin films with an average pore size of $24 \mathrm{~nm}$ revealed no signs of proton conduction at temperatures above $250^{\circ} \mathrm{C}$. Instead, a reduction of oxygen ion conductivity was found, which was attributed to the annihilation of oxygen ion vacancies at the surface due to water adsorption and the formation of hydroxyl ions. ${ }^{35}$

The situation changes completely when the surface of the porous YSZ thin film is coated with a $\mathrm{TiO}_{2}$ layer, as shown in Figs. 5 (b) and (c). Although the pore size is decreased in these samples, i.e., capillary condensation should be more favorable, the coated YSZ thin films exhibit a significantly reduced protonic conductivity compared to the as-prepared porous YSZ thin film. At temperatures above $400{ }^{\circ} \mathrm{C}, \mathrm{YSZ} / \mathrm{aTiO}_{2}(6 \mathrm{~nm})$ shows no protonic conductivity contribution anymore and, in the temperature range between 150 and $400{ }^{\circ} \mathrm{C}$, the proton conductivity is only observed for $\mathrm{RH}>10 \%$. At lower temperatures, an increase in conductivity with decreasing temperature and increasing $\mathrm{RH}$ is found, as typically observed for porous $\mathrm{TiO}_{2} \cdot{ }^{18-21} \mathrm{In}$ the case of $\mathrm{YSZ} / \mathrm{CTiO}_{2}(18 \mathrm{~nm})$, the protonic conductivity increases again with a protonic contribution even at temperatures above $400{ }^{\circ} \mathrm{C}$, as shown in Fig. 5 (c), but it still remains lower compared to the uncoated thin film.

The decrease in conductivity compared to the uncoated material is attributed to the different hydrophilic properties of the $\mathrm{TiO}_{2}$ surfaces. While water on YSZ surfaces is adsorbed mainly in its dissociative form, ${ }^{67}$ the $\mathrm{TiO}_{2}$ surfaces are predominantly covered by molecular water. ${ }^{73}$ Thus, the $\mathrm{TiO}_{2}$ surfaces exhibit a lower coverage with hydroxyl groups, which are responsible for the proton conduction in the chemisorbed layer. ${ }^{11}$ This behavior can be attributed mainly to the reduced amount of oxygen vacancies on $\mathrm{TiO}_{2}$ surfaces compared to $\mathrm{YSZ}$, which act as active sites for water adsorption. $69,70,74$ Furthermore, DFT calculations suggest that on amorphous $\mathrm{TiO}_{2}$ the adsorption of hydroxyl groups is even less favorable compared to anatase $\mathrm{TiO}_{2},{ }^{75}$ which is also supported by the lower protonic conductivity in the case of the amorphous coating, especially at higher temperatures. However, water condensation in the pores may also play a role in the higher protonic conductivity in the case of the YSZ thin film with the crystalline $\mathrm{TiO}_{2}$ (note that the pore size is also reduced due to the coating).

To gain further insights in the transport mechanism, the conductivity at fixed $\mathrm{RH}$ was plotted as a function of the inverse temperature (Fig. 7). For all three samples and RHs tested, a linear Arrhenius-type behavior is found, where the activation energy depends on the enthalpies of defect formation $\Delta H_{\mathrm{D}}$ and mobility $\Delta H_{\text {mob }}{ }^{11,13}$

$$
E_{\mathrm{A}}=\frac{1}{2} \Delta H_{\mathrm{D}}+\Delta H_{\mathrm{mob}}
$$

The activation energy of the transport process was determined by linear fitting of $\log (\sigma T)$ versus the reciprocal temperature $1 / T$ and is shown as a function of $\mathrm{RH}$ in Fig. 8 . At $10 \% \mathrm{RH}$, the YSZ thin film exhibits an activation energy of about $0.59 \mathrm{eV}$, which decreases with increasing $\mathrm{RH}$. The comparable values for the activation energy of proton transport in porous YSZ (varying between 0.3 and $0.6 \mathrm{eV}$ ) and a decrease in $E_{\mathrm{A}}$ with increasing $\mathrm{RH}$ were reported by other groups. ${ }^{11,13,34}$ Stub et al. interpreted the linear decrease in $E_{A}$ with a change in the dominant transport mechanism from Grotthuss-type to vehicle-type transport, which was supported by measurements of the apparent proton transference number. ${ }^{13}$ 


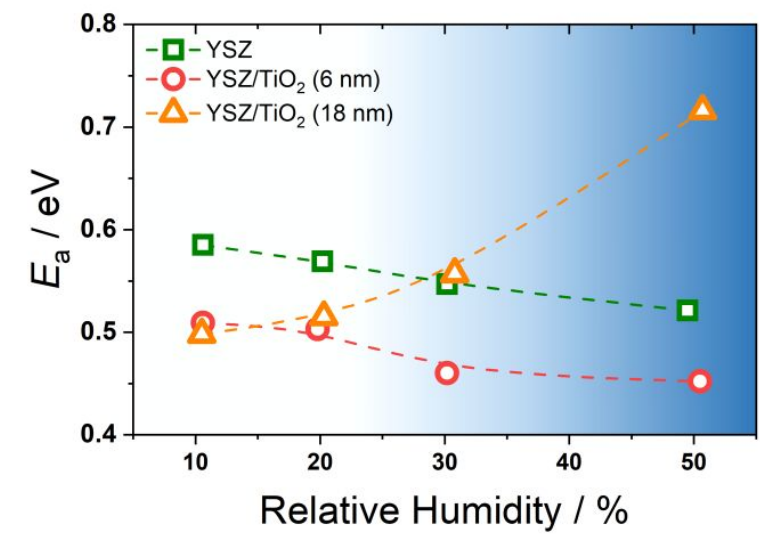

Figure 8. Activation energy as a function of relative humidity for porous (annealed) $\mathrm{YSZ},(\mathrm{b}) \mathrm{YSZ} / \mathrm{aTiO}_{2}(6 \mathrm{~nm})$ and (c) $\mathrm{YSZ}_{2} \mathrm{cTiO}_{2}(18$ $\mathrm{nm})$.

However, a change in defect formation enthalpy with RH may also affect $E_{\mathrm{A}}$. For the porous YSZ thin film coated with amorphous $\mathrm{TiO}_{2}$, the same behavior is observed, in agreement with other reports available in literature, ${ }^{20}$ indicating the same change in dominant transport mechanism as observed for the uncoated YSZ. However, a slightly reduced activation energy of $0.5 \mathrm{eV}$ is determined at low $\mathrm{RH}$. The lower activation energy compared to pristine YSZ is attributed to a lower $\Delta H_{\mathrm{D}}$, as the same value is also observed for the thin film coated with anatase $\mathrm{TiO}_{2}$. Interestingly, the activation energy is found to increase with increasing $\mathrm{RH}$ for $\mathrm{YSZ} / \mathrm{CTiO}_{2}(18 \mathrm{~nm})$. A similar finding was made by Vichi et al., ${ }^{19}$ who also studied protonic conductivity in mesoporous $\mathrm{TiO}_{2}$. They attributed the change in activation energy to a decrease in mobility, i.e., an increase in $\Delta$

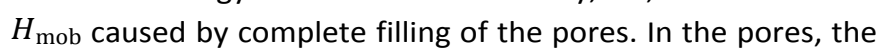
water molecules form bridges between the hydrated pore walls, leading to the observed decrease in mobility. The same should be true for the anatase-coated YSZ thin film, as the pore size is significantly reduced by the $18 \mathrm{~nm}$-thick coating.

\section{Conclusions}

To investigate the influence of free surface on the electronic and protonic transport properties in oxides, porous YSZ thin films were prepared by PLD and characterized using electrochemical impedance spectroscopy. Under high humidity conditions, the porous YSZ revealed a significant increase in total conductivity due to protonic transport taking place at the surface. Modifying the surface by depositing an amorphous $\mathrm{TiO}_{2}$ layer of $6 \mathrm{~nm}$ thickness using ALD resulted in an additional electronic transport pathway in the coating under dry atmosphere, while under humidified conditions, the protonic conductivity contribution was significantly suppressed. After deposition of an $18 \mathrm{~nm}$-thick anatase coating, the protonic conductivity increased again because of filling of the reducedsize pores with water. Furthermore, with increasing humidity, the activation energy of the transport process also increased, which is attributed to a decrease in proton mobility when the pores are filled with water. The results demonstrate that not only the porosity but also the surface properties have a strong effect on the protonic transport, which may help in designing and optimizing proton-conducting (nanoscale) oxides for technological applications through tailored surface modification.

\section{Conflicts of interest}

There are no conflicts to declare.

\section{Acknowledgements}

We thank Karlsruhe Nano Micro Facility (KNMF), a Helmholtz Research Infrastructure at Karlsruhe Institute of Technology (KIT) for TEM. Financial support by the German Research Foundation (to T.B., grant no. BR 3499/5-1 and to M.T.E., grant no. EL $863 / 3-1$ ) is gratefully acknowledged. M.T.E., R.S.N. and M.B. thank the German Federal Ministry of Education and Research (BMBF) for funding of the NanoMatFutur project NiKo (03ХP0093).

\section{Notes}

There are no conflicts to declare.

\section{References}

1 H. L. Tuller, lonic conduction in nanocrystalline materials, Solid State lonics, 2000, 131, 143-157.

2 J. Maier, On the Conductivity of Polycrystalline Materials, Berichte der Bunsengesellschaft für Phys. Chemie, 1986, 90, 26-33.

3 J. Maier, Pushing Nanoionics to the Limits: Charge Carrier Chemistry in Extremely Small Systems, Chem. Mater., 2014, 26, 348-360.

J. Maier, Nanoionics: ion transport and electrochemical storage in confined systems, Nat. Mater., 2005, 4, 805815.

5

G. Gregori, R. Merkle and J. Maier, lon conduction and redistribution at grain boundaries in oxide systems, Prog. Mater. Sci., 2017, 89, 252-305.

6 J. Maier, lonic conduction in space charge regions, Prog. Solid State Chem., 1995, 23, 171-263.

7 J. Maier, Thermodynamics of Nanosystems with a Special View to Charge Carriers, Adv. Mater., 2009, 21, 2571-2585.

8 A. Tschöpe, E. Sommer and R. Birringer, Grain sizedependent electrical conductivity of polycrystalline cerium oxide: I. Experiments, Solid State Ionics, 2001, 139, 255265.

9 X. Guo and R. Waser, Space charge concept for acceptordoped zirconia and ceria and experimental evidences, Solid State lonics, 2004, 173, 63-67.

10 J. Yue, C. Suchomski, P. Voepel, R. Ellinghaus, M. Rohnke, T. Leichtweiss, M. T. Elm and B. M. Smarsly, Mesoporous 
niobium-doped titanium dioxide films from the assembly of crystalline nanoparticles: study on the relationship between the band structure, conductivity and charge storage mechanism, J. Mater. Chem. A, 2017, 5, 19781988.

11 S. Raz, K. Sasaki, J. Maier and I. Riess, Characterization of adsorbed water layers on Y2O3-doped $\mathrm{ZrO2}$, Solid State lonics, 2001, 143, 181-204.

12 B. Scherrer, M. V. F. Schlupp, D. Stender, J. Martynczuk, J. G. Grolig, H. Ma, P. Kocher, T. Lippert, M. Prestat and L. J. Gauckler, On Proton Conductivity in Porous and Dense Yttria Stabilized Zirconia at Low Temperature, Adv. Funct. Mater., 2013, 23, 1957-1964.

13 S. $\varnothing$. Stub, E. Vøllestad and T. Norby, Mechanisms of Protonic Surface Transport in Porous Oxides: Example of YSZ, J. Phys. Chem. C, 2017, 121, 12817-12825.

G. Gregori, M. Shirpour and J. Maier, Proton Conduction in Dense and Porous Nanocrystalline Ceria Thin Films, Adv. Funct. Mater., 2013, 23, 5861-5867.

15 H. J. Avila-Paredes, C.-T. Chen, S. Wang, R. A. De Souza, M. Martin, Z. Munir and S. Kim, Grain boundaries in dense nanocrystalline ceria ceramics: exclusive pathways for proton conduction at room temperature, J. Mater. Chem., 2010, 20, 10110-10112.

16 M. Shirpour, G. Gregori, R. Merkle and J. Maier, On the proton conductivity in pure and gadolinium doped nanocrystalline cerium oxide, Phys. Chem. Chem. Phys., 2011, 13, 937-940.

17 E. Ruiz-Trejo and J. A. Kilner, Possible proton conduction in Ce0.9Gd0.102- $\delta$ nanoceramics, J. Appl. Electrochem., 2009, 39, 523-528.

18 I. G. Tredici, F. Maglia, C. Ferrara, P. Mustarelli and U. Anselmi-Tamburini, Mechanism of Low-Temperature Protonic Conductivity in Bulk, High-Density, Nanometric Titanium Oxide, Adv. Funct. Mater., 2014, 24, 5137-5146. F. M. Vichi, M. I. Tejedor-Tejedor and M. A. Anderson, Effect of Pore-Wall Chemistry on Proton Conductivity in Mesoporous Titanium Dioxide, Chem. Mater., 2000, 12, 1762-1770.

20 M. T. Colomer, Nanoporous Anatase Thin Films as Fast Proton-Conducting Materials, Adv. Mater., 2006, 18, 371374.

21 F. Maglia, I. G. Tredici, G. Spinolo and U. AnselmiTamburini, Low temperature proton conduction in bulk nanometric TiO2 prepared by high-pressure field assisted sintering, J. Mater. Res., 2012, 27, 1975-1981.

22 L. Almar, A. Tarancón, T. Andreu, M. Torrell, Y. Hu, G. Dezanneau and A. Morata, Mesoporous ceramic oxides as humidity sensors: A case study for gadolinium-doped ceria, Sensors Actuators B Chem., 2015, 216, 41-48.

23 H. Farahani, R. Wagiran and N. M. Hamidon, Sensors, 2014, 14.

24 X. Q. Fu, C. Wang, H. C. Yu, Y. G. Wang and T. H. Wang, Fast humidity sensors based on $\mathrm{CeO} 2$ nanowires,

Nanotechnology, 2007, 18, 145503.

25 S. Kim, U. Anselmi-Tamburini, H. J. Park, M. Martin and Z.

A. Munir, Unprecedented Room-Temperature Electrical
Power Generation Using Nanoscale Fluorite-Structured Oxide Electrolytes, Adv. Mater., 2008, 20, 556-559.
26 R. Manabe, S. Okada, R. Inagaki, K. Oshima, S. Ogo and Y. Sekine, Surface Protonics Promotes Catalysis, Sci. Rep., 2016, 6, 38007.

S. Kim, H. J. Avila-Paredes, S. Wang, C.-T. Chen, R. A. De Souza, M. Martin and Z. A. Munir, On the conduction pathway for protons in nanocrystalline yttria-stabilized zirconia, Phys. Chem. Chem. Phys., 2009, 11, 3035-3038. H. J. Avila-Paredes, J. Zhao, S. Wang, M. Pietrowski, R. A. De Souza, A. Reinholdt, Z. A. Munir, M. Martin and S. Kim, Protonic conductivity of nano-structured yttria-stabilized zirconia: dependence on grain size, J. Mater. Chem., 2010, 20, 990-994.

9 G. Chiodelli, F. Maglia, U. Anselmi-Tamburini and Z. A. Munir, Characterization of low temperature protonic conductivity in bulk nanocrystalline fully stabilized zirconia, Solid State lonics, 2009, 180, 297-301.

W. C. Chueh, C.-K. Yang, C. M. Garland, W. Lai and S. M. Haile, Unusual decrease in conductivity upon hydration in acceptor doped, microcrystalline ceria, Phys. Chem. Chem. Phys., 2011, 13, 6442-6451.

S. $\varnothing$. Stub, E. Vøllestad and T. Norby, Protonic surface conduction controlled by space charge of intersecting grain boundaries in porous ceramics, J. Mater. Chem. A, 2018, 6, 8265-8270.

S. $\varnothing$. Stub, K. Thorshaug, P. M. Rørvik, T. Norby and E. Vøllestad, The influence of acceptor and donor doping on the protonic surface conduction of TiO2, Phys. Chem. Chem. Phys., 2018, 20, 15653-15660.

S. Miyoshi, Y. Akao, N. Kuwata, J. Kawamura, Y. Oyama, T. Yagi and S. Yamaguchi, Low-Temperature Protonic Conduction Based on Surface Protonics: An Example of Nanostructured Yttria-Doped Zirconia, Chem. Mater., 2014, 26, 5194-5200.

S. Miyoshi, Y. Akao, N. Kuwata, J. Kawamura, Y. Oyama, T. Yagi and S. Yamaguchi, Water uptake and conduction property of nano-grained yttria-doped zirconia fabricated by ultra-high pressure compaction at room temperature, Solid State lonics, 2012, 207, 21-28.

M. T. Elm, J. D. Hofmann, C. Suchomski, J. Janek and T. Brezesinski, lonic Conductivity of Mesostructured YttriaStabilized Zirconia Thin Films with Cubic Pore SymmetryOn the Influence of Water on the Surface Oxygen Ion Transport, ACS Appl. Mater. Interfaces, 2015, 7, 1179211801.

J. L. Hertz and H. L. Tuller, Electrochemical Characterization of Thin Films for a Micro-Solid Oxide Fuel Cell, J.

Electroceramics, 2004, 13, 663-668.

J. J. Neumeier, M. T. Elm, B. Luerßen and J. Janek, Platinum microelectrodes on gadolinia doped ceria single crystals bulk properties and electrode kinetics, Phys. Chem. Chem. Phys., 2018, 20, 8294-8301.

N. Otsu, A Threshold Selection Method from Gray-Level Histograms, IEEE Trans. Syst. Man. Cybern., 1979, 9, 62-66. M. Yashima, S. Sasaki, M. Kakihana, Y. Yamaguchi, H. Arashi and $M$. Yoshimura, Oxygen-induced structural change of 
the tetragonal phase around the tetragonal-cubic phase boundary in ZrO2-YO1.5 solid solutions, Acta Crystallogr. Sect. B, , DOI:10.1107/S0108768194006257.

40 P. Debye, P., Scherrer, Atombau, Nachrichten von der Gesellschaft der Wissenschaften zu Göttingen, Math. Klasse, 1918, 1918, 101-120.

41 P. Briois, F. Lapostolle, V. Demange, E. Djurado and A. Billard, Structural investigations of YSZ coatings prepared by DC magnetron sputtering, Surf. Coatings Technol., 2007, 201, 6012-6018.

42 R. Srinivasan, R. J. De Angelis, G. Ice and B. H. Davis, Identification of tetragonal and cubic structures of zirconia using synchrotron x-radiation source, J. Mater. Res., 1991, 6, 1287-1292.

43 A. Aminzadeh and H. Sarikhani-fard, Raman spectroscopic study of Ni/Al2O3 catalyst, Spectrochim. Acta Part A Mol. Biomol. Spectrosc., 1999, 55, 1421-1425.

44 M. Kadléíková, J. Breza and M. Veselý, Raman spectra of synthetic sapphire, Microelectronics J., 2001, 32, 955-958.

J. Cai, C. Raptis, Y. S. Raptis and E. Anastassakis,

Temperature dependence of Raman scattering in stabilized cubic zirconia, Phys. Rev. B, 1995, 51, 201-209.

S. K. Mukherjee and D. Mergel, Thickness dependence of the growth of magnetron-sputtered $\mathrm{TiO} 2$ films studied by Raman and optical transmittance spectroscopy, J. Appl. Phys., 2013, 114, 13501.

47 T. Ohsaka, F. Izumi and Y. Fujiki, Raman spectrum of anatase, TiO2, J. Raman Spectrosc., 1978, 7, 321-324. O. Frank, M. Zukalova, B. Laskova, J. Kürti, J. Koltai and L. Kavan, Raman spectra of titanium dioxide (anatase, rutile) with identified oxygen isotopes $(16,17,18)$, Phys. Chem. Chem. Phys., 2012, 14, 14567-14572.

49 D. R. G. Mitchell, D. J. Attard and G. Triani, Transmission electron microscopy studies of atomic layer deposition TiO2 films grown on silicon, Thin Solid Films, 2003, 441, 8595.

50 J. T. S. Irvine, D. C. Sinclair and A. R. West, Electroceramics: Characterization by Impedance Spectroscopy, Adv. Mater., 1990, 2, 132-138.

51 M. Gerstl, E. Navickas, G. Friedbacher, F. Kubel, M. Ahrens and J. Fleig, The separation of grain and grain boundary impedance in thin yttria stabilized zirconia (YSZ) layers, Solid State lonics, 2011, 185, 32-41.

52 C. Ahamer, A. K. Opitz, G. M. Rupp and J. Fleig, Revisiting the Temperature Dependent lonic Conductivity of Yttria Stabilized Zirconia (YSZ), J. Electrochem. Soc. , 2017, 164, F790-F803.

53 M. Bastianello, S. Gross and M. T. Elm, Thermal stability, electrochemical and structural characterization of hydrothermally synthesised cobalt ferrite (CoFe2O4), RSC Adv., 2019, 9, 33282-33289. Percent Y 203 -ZrO2, J. Electrochem. Soc. , 1989, 136, 2867-2876.

55 M. A. Parkes, D. A. Tompsett, M. d'Avezac, G. J. Offer, N. P. Brandon and N. M. Harrison, The atomistic structure of yttria stabilised zirconia at $6.7 \mathrm{~mol} \%$ : an ab initio study,
Phys. Chem. Chem. Phys., 2016, 18, 31277-31285.

X. Guo, E. Vasco, S. Mi, K. Szot, E. Wachsman and R. Waser, Ionic conduction in zirconia films of nanometer thickness, Acta Mater., 2005, 53, 5161-5166.

S. Ikeda, O. Sakurai, K. Uematsu, N. Mizutani and M. Kato, Electrical conductivity of yttria-stabilized zirconia single crystals, J. Mater. Sci., 1985, 20, 4593-4600.

J. Jiang and J. L. Hertz, On the variability of reported ionic conductivity in nanoscale YSZ thin films, J. Electroceramics, 2014, 32, 37-46.

D. Adler, Amorphous semiconductors, C R C Crit. Rev. Solid State Sci., 1971, 2, 317-465.

H. Takikawa, T. Matsui, T. Sakakibara, A. Bendavid and P. J. Martin, Properties of titanium oxide film prepared by reactive cathodic vacuum arc deposition, Thin Solid Films, 1999, 348, 145-151.

61 S. B. Amor, L. Guedri, G. Baud, M. Jacquet and M. Ghedira, Influence of the temperature on the properties of sputtered titanium oxide films, Mater. Chem. Phys., 2003, 77, 903-911.

M. K. Nowotny, L. R. Sheppard, T. Bak and J. Nowotny, Defect Chemistry of Titanium Dioxide. Application of Defect Engineering in Processing of TiO2-Based Photocatalysts, J. Phys. Chem. C, 2008, 112, 5275-5300. T. Bak, J. Nowotny, M. Rekas and C. C. Sorrell, Defect chemistry and semiconducting properties of titanium dioxide: II. Defect diagrams is, J. Phys. Chem. Solids, 2003, 64, 1057-1067.

A. Weibel, R. Bouchet and P. Knauth, Electrical properties and defect chemistry of anatase (TiO2), Solid State lonics, 2006, 177, 229-236.

A. M. Azad, S. A. Akbar, L. B. Younkman and M. A. Alim, High-Temperature Immittance Response in Anatase-Based Sensor Materials, J. Am. Ceram. Soc., 1994, 77, 3145-3152. S.-H. Song, X. Wang and P. Xiao, Effect of microstructural features on the electrical properties of TiO2, Mater. Sci. Eng. B, 2002, 94, 40-47. E.-M. Köck, M. Kogler, B. Klötzer, M. F. Noisternig and S. Penner, Structural and Electrochemical Properties of Physisorbed and Chemisorbed Water Layers on the Ceramic Oxides Y2O3, YSZ, and ZrO2, ACS Appl. Mater. Interfaces, 2016, 8, 16428-16443.

R. Schaub, P. Thostrup, N. Lopez, E. Lægsgaard, I. Stensgaard, J. K. Nørskov and F. Besenbacher, Oxygen Vacancies as Active Sites for Water Dissociation on Rutile \$\{\mathrm\{TiO\}\}_\{2\}(110)\$, Phys. Rev. Lett., 2001, 87, 266104.

B. Hou, S. Kim, T. Kim, J. Kim, S. Hong, C. B. Bahn, C. Park and J. H. Kim, The Hydration Structure at Yttria-Stabilized Cubic Zirconia (110)-Water Interface with Sub-Ångström Resolution, Sci. Rep., 2016, 6, 27916. O. Bikondoa, C. L. Pang, R. Ithnin, C. A. Muryn, H. Onishi and $\mathrm{G}$. Thornton, Direct visualization of defect-mediated dissociation of water on TiO2(110) , Nat. Mater., 2006, 5, 189-192.

$71 \quad \mathrm{X}$. Guo, On the degradation of zirconia ceramics during low-temperature annealing in water or water vapor, $J$. 
Phys. Chem. Solids, 1999, 60, 539-546.

72 K.-D. Kreuer, Proton Conductivity: Materials and Applications, Chem. Mater., 1996, 8, 610-641.

73 A. Ignatchenko, D. G. Nealon, R. Dushane and K. Humphries, Interaction of water with titania and zirconia surfaces, J. Mol. Catal. A Chem., 2006, 256, 57-74.

74 Y. Li and Y. Gao, Interplay between Water and \$\{\mathrm\{TiO\}\}_\{2\}\$ Anatase (101) Surface with Subsurface Oxygen Vacancy, Phys. Rev. Lett., 2014, 112, 206101.

75 K. K. Ghuman, Mechanistic insights into water adsorption and dissociation on amorphous TiO2-based catalysts, Sci. Technol. Adv. Mater., 2018, 19, 44-52. 